\title{
NUEVOS ADULTOS PARA LA EDUCACIÓN PARVULARIA. CUIDADO Y BUEN VIVIR DESDE LA BIODANZA Y EL PRINCIPIO BIOCÉNTRICO
}

New adults for preschool education.

Care and good living from the biodance and biocentric principle

Nova educação de adultos pré-escolar.

Cuidados e bom viver a partir da biodanza e princípio biocêntrico

\section{Loreto Libuy Castro}

Universidad Austral de Chile, Chile. Fono: +56 63 2293823. Correo electrónico: loretolibuy@gmail.com

\section{Resumen}

Las actuales reformas y proyectos de ley en Chile, buscan proporcionar cambios que apuntan aparentemente al mejoramiento de la calidad de vida de las personas, pero no se detienen en el cuidado profundo de aquellos que trabajan día a día con los más pequeños de nuestra sociedad. Esta propuesta intenta exponer el sentir de adultos responsables de la educación en prescolares, considerando tanto a padres como a educadoras de párvulos, quienes constantemente olvidan el propio cuidado en pos de un seudobeneficio hacia niñas y niños. La metodología concreta que da respuesta a esta problemática, está basada en la experiencia de biodanza y el principio biocéntrico, como disciplinas y bases epistémicas educacionales emergentes que buscan armonizar los gestos despedazados de la vida, desde la vivencia corpórea, musical y el continente afectivo. Además de un diagnóstico y un abordaje general del problema, el presente artículo propone una forma explícita del manejo del buen vivir, haciendo una distinción clara de lo que comúnmente se entiende por bien estar. Por su parte, el relato de experiencias didácticas con educadoras de párvulos, permite visualizar de manera concreta la metodología propuesta. Toro (2008, 2012), Boff (2006), Albó (2009) y Cornejo (2009), son sólo algunos de los autores que acompañan esta reflexión-acción.

Palabras Claves: Educación Parvularia, Buen Vivir, Biodanza, Principio Biocéntrico.

\section{Abstract}


The Current reforms and law projects in Chile, seek to provide changes that seemingly aim at improving the quality of life of people, but they do not stop under the deep care of those who work daily with the children of our society. This proposal seeks to expose the feelings of adults responsible for preschool education, taking into consideration as much to parents as to kindergarten educators, who constantly forget the proper care in search of a pseudo benefit to children. The specific methodology that responds to this problem is based on the experience of biodance and biocentric principle, as disciplines and emerging educational epistemic bases that seek to harmonize torn gestures of life, from the corporeal experience, musical and affective continent. In addition to a diagnosis and a general approach to the problem, this paper proposes an explicit management of good living, making a clear distinction of what is commonly understands by well-being. Meanwhile, the short story of learning experiences with kindergarten educators, allow to visualize concretely the proposed methodology. Toro (2008, 2012), Boff (2006), Albo (2009) and Cornejo (2009) are just some of the authors that accompany this reflection-action.

Keywords: Preschool Education, Good Living, Biodance, Biocentric Principle.

\section{Resumo}

As atuais reformas e projetos da lei em Chile, se procuram proporcionar mudanças que visam aparentemente ao melhoramento da qualidade de vida das pessoas, além disso, não tem em conta de forma profunda o caso de aqueles que trabalham diariamente com poucas posibilidades da nossa sociedade. Através deste trabalho tenta de expor como adultos responsaveis da educação infantil, considerando tanto os país como os educadores da creche, quem muitas vezes esquecem do seu proprío cuidado pelo beneficio das crianças. A metodología concreta que dá resposta a esta problemática, está baseada na experiencia de biodanza e o principio biocêntrico, como disciplinas e bases epistémicas educacionais emergentes que buscam uma armonía do gestos despedaçados da vida, a partir de uma vivência corpórea, musical e no campo afetivo. Tendo em conta o diagnóstico e a abordagem geral do problema, o presente artigo propõe uma maneira explícita como levar a cabo uma boa vida, estabelecendo de forma clara a diferencia entre o que geralmente se entende por bem estar. Por sua parte, o relato de experiencias didática com educadores das 
creches, permite ver de forma concreta a metodología proposta. Toro (2008, 2012), Boff (2006), Albó (2009) e Cornejo (2009), são os principaís autores que nos ajudam nesta reflexão-ação.

\section{Palavras-chave: Educação Pré-Escolar, Bom Viver, Biodanza, Princípio Biocêntrico.}

\section{Presentación}

Seguir escarbando en lo mal que está la educación chilena, es escapar de la responsabilidad que poseemos cada uno de nosotros en esta historia. Más que denunciar hechos, esta vez la propuesta es una apuesta que invita a la renovación en la forma de visualizar la labor docente, a partir de la especificidad de la profesión parvularia y su relación con los adultos que acompañan este proceso. No se trata de entregar la solución definitiva al problema, pero si aportar con métodos que hagan del quehacer educativo un camino más noble y fluído.

Desde que comienza el milagro de la vida humana, existen potenciales biológicos que sólo buscan una instancia para poder expresarse. Sin embargo, la falta de oportunidades, muchas veces contextuales y culturales, no permiten que aquello ocurra en todo su esplendor, y cuando comienzan a manifestarse los adultos nos encargamos de apagar y reprimir las diversas capacidades creativas que tienen una niña o un niño. Pero esta negación no es sólo responsabilidad de los profesores, también hay desconfianza de los talentos infantiles en cualquier individuo que supere la adolescencia, vale decir, adultos ${ }^{1}$.

El tema es que no somos educados para calificar al otro, más bien tendemos a descalificar y hacer notar aquello que se debe corregir, dejando de lado las virtudes que nos hacen estar vivos. En este sentido, hablar de nuevos adultos desde el principio biocéntrico y el buen vivir, invita a detener la mirada educativa en los ecofactores positivos que rodean a cada humano (niño o adulto), haciendo énfasis en lo sagrado de la existencia, pero no desde el discurso ni de reformas normadas en artículos de ley, sino que desde el cuerpo, desde el sentir la vibración cutánea en las aulas y en la vida misma. A partir de ello, se deduce que

\footnotetext{
${ }^{1}$ Según la psicología del desarrollo, adulto es aquel que supera los veinte años de edad y culmina su primera etapa hacia los cuarenta, para luego comenzar la adultez media que se extiende hasta los sesenta o sesenta y cinco años. Sin embargo, ser adulto considera mucho más que la edad, algunos viajarán dignamente y con orgullo, mientras otros lo harán cargados de limitaciones físicas, ambientales y emocionales.
} 
no hay transformación sin vivencia, entendida ésta como la experiencia con viveza, por lo tanto no hay cambio si no hay intensidad y desafío.

El principio biocéntrico (Alonso, 2014) es un enfoque basado en el respeto por la vida, donde ésta es el centro y el punto de partida de todas las disciplinas y comportamientos humanos, valora la sacralidad de la misma y las culturas deben estar organizadas a partir de ella. Las danzas, las expresiones y todo acto son dignos de respeto en sí mismos. En este contexto, la acción humana y educativa responde a necesidades del pluriverso. Es así como toda comunidad viva trabaja en grupo y conecta con la belleza del ser humano desarrollando relaciones que nos hacen más integrados y completos.

Por su parte, la biodanza como disciplina biocéntrica para adultos responsables de la educación de infantes, busca sembrar y fomentar la semilla del ser ellos mismos, donde la confianza, seguridad y autoestima se expanden primero desde el adulto que forma. En este sentido, la escuela es perfecta para integrar las dimensiones corpóreas, emocionales y trascendentales de quienes la habitan, por tanto los adultos conscientes pueden servir de guía en el mágico proceso de co-construir un mundo mejor. Si docentes y padres no comprenden desde la vivencia corpórea estos desafíos, las intenciones se quedan en el discurso.

Cuando se habla de buen vivir, se hace referencia a una forma de existencia donde el cobijo y la morada están dados por la relación agradable con los semejantes, donde el bien estar propio es el bien estar del otro, donde las conversaciones son primordiales y la energía luminosa/numinosa ${ }^{2}$ son la fuente de energía vital. Desde este punto de vista, buen vivir es un paso más trascendente que el sólo bien estar.

Al ser capaces de entrelazar estos conceptos en beneficio de la educación parvularia, se diseñará una renovación afectiva-pedagógica en la forma de abordar el trato con los pequeños-gigantes de la escala humana.

\footnotetext{
${ }^{2}$ Numinoso: referido a la manifestación de poderes divinos. Deriva del latín neu (numen) referido a las deidades romanas. También se usa para referirse al ingenio poético. Abarca el sentido sagrado y la inmanencia de la religión romana. Cuando se habla de Inconsciente Numinoso, hace noción a percibir la armonía de la música de las esferas y la sutileza de la divinidad que nace en cada ser vivo que danza en profundidad.
} 


\section{Cuidado, buen vivir y principio biocéntrico}

Cuando Leonardo Boff habla del "cuidado esencial", se refiere a un nuevo paradigma humano que definirá la esencia del ser mediante el cuidado como actitud fundamental hacia sí mismo y hacia el mundo, por lo que se hace fundamental la responsabilización y un compromiso afectivo con el otro. En palabras de Álamo (2011), Boff advierte tres dimensiones de la existencia humana: material y terrenal, espiritual y celestial y utópica.

La primera dimensión se refiere a que "somos tierra", comprendiendo que biológicamente estamos constituidos por los mismos elementos y macroelementos que la conforman. A pesar de ello, la tendencia humana es alejarse y pensarla como algo fuera de nosotros; se agrede y abusa sin percibir que estas acciones son un autoflagelo. Sin embargo, su principio generativo que engendra, da vida y acoge, es todavía rescatado por diferentes culturas originarias, donde sin hacer mayores distinciones, vivencian la segunda dimensión expuesta por Boff (2006) relacionada a lo espiritual y celestial del ser humano. En este espacio, se busca la trascendencia a través de la superación de las limitaciones propias de hombres y mujeres terrestres. No obstante, si los impulsos no son equilibrados y dosificados se puede caer facilmente en el deseo de acaparar bienes sin necesidad alguna. Para encontrar la armonía entre estas dos dimensiones es preciso explicar la dimensión utópica. La utopía es la forma en la que el deseo terrenal se abre hacia nuevas perspectivas y hace posible las dos anteriores, pero lo que hace que la utopía cobre sentido es nuestra cualidad de ser seres para el cuidado, vale decir, salir del sí mismo y centrarse en el otro con desvelo y solicitud.

Desde las perspectivas anteriores, hablar de buen vivir es comprender que no se trata de "vivir mejor", lo que se busca es “vivir bien”. En el preámbulo de la constitución boliviana, el año 2009, se anuncian las virtudes que debería tener la nueva Bolivia, donde la igualdad, la armonía y la equidad son sólo algunas de las cualidades que desafían a esta normativa gubernamental, buscando la predominancia del "vivir bien”. Albó (2009: 26), señala que "a veces las traducciones son traicioneras", y algo de ello ocurre en el "vivir bien", si es que no se contextualiza en la lengua y cultura dentro de la que fue acuñada en su forma original. 
Específicamente, el autor habla de suma qamaña que significa habitar agradable, vivir bien o morar amable en lengua aymara. Las culturas andinas, tanto quechuas como aymaras reconocen, según Albó (2009: 27) “que las suyas son culturas para la vida, no se refieren sólo a este hecho físico de vivir, sino también a todo este conjunto de relaciones sociales con un ambiente de acogida. Por eso se habla además de cuidar y criar la vida, como algo que hacemos juntos, en familia”. Esta comprensión trascendente y social del vivir bien, se entiende porque SUMA significa bonito, hermoso, agradable, bueno y amable, mientras que QAMAÑA se refiere a habitar, vivir, morar, cobijar, pero no en soledad, sino que en conjunto. El autor antes mencionado, indica que qamaña era un refugio semicircular de piedra donde los pastores andinos se cobijaban del viento para cuidar desde ahí a sus rebaños; a esto se agrega que era el momento en que compartían conversaciones y mates con otros pastores del sector, por lo tanto suma qamaña no sólo significa vivir bien, sino que "buen convivir".

¿Por qué estas culturas se resisten a hablar de “vivir mejor”?. Albó (2009: 28), plantea que "los pueblos originarios andinos no lo ven necesario porque la palabra suma ya involucra en sí misma el mayor grado posible”. Por otra parte, el decir mejor se entiende como que un individuo o grupo vive y está mejor que otros y a costa de otros. En este contexto, se puede inferir que cuando se habla de "bien estar" también su significado se reduce a una acción estática e individualista que no involucra a la comunidad en la que se co-habita, más bien existe, consciente o inconscientemente, una negación de las otras vidas que nos rodean.

Los dos conceptos analizados (cuidado y buen vivir), tienen directa relación con el principio biocéntrico levantado por Rolando Toro, creador del sistema biodanza. El psicólogo chileno formuló el "Principio Biocéntrico" en el año 1970, inspirado en el pensamiento de que el universo está organizado en función de la vida. La vida sería, según este abordaje, un proyecto-fuerza que conduce, a través de millones de años, la evolución del cosmos. Para Toro (2008: 73), “es ingenuo pensar que la vida es el resultado ocasional de la combinatoria de elementos atómicos, la posibilidad que se genere un organismo vivo por la combinación fortuita de elementos, sin una matriz organizadora previa, es 
impensable". Para este intelectual chileno, el universo existe porque existe la vida, y no al revés. Variados científicos estudiados por Toro Araneda, han llegado a la conclusión que el universo es un gigantesco holograma vivo, y esto sólo se puede comprender desde experiencia místicas y de identidad suprema.

El principio biocéntrico sitúa el respeto por la vida como centro y punto de partida de todas las disciplinas y comportamientos humanos. La propuesta es situar "la vida al centro" de todas las actividades humanas, en particular en la educación, la psicoterapia, la medicina, la economía y la jurisprudencia. Este modelo es quizás el abordaje más apropiado para pensar "la educación" en un contexto de totalidad, que promueve la potenciación de la vida y la expresión de sus poderes evolutivos, teniendo como importante forma de despliegue a la biodanza y la educación biocéntrica.

Biodanza es en sistema de integración afectiva, de renovación orgánica y de reaprendizaje de las funciones originarias de la vida, donde la sesión implica vivencias profundas realizadas en grupos humanos que danzan, juegan, trascienden y se emocionan. Considera cinco líneas de vivencia fundamentales: vitalidad, creatividad, sexualidad, afectividad y trascendencia. Estos elementos provocan la deflagración de potenciales latentes, a veces adormicidos y/o reprimidos por nuestra cultura. El sistema despierta y eleva el humor endógeno trabajado fundamentalmente desde una curva metodológica que transita entre polos opuestos de energías, donde el vaivén de sensaciones, junto a las semánticas musicales propuestas, permiten abrir canales de comunicación afectiva que armonizan el sistema límbico-hipotalámico con el sistema endocrino y el sistema nervioso.

Dicha disciplina encuentra un gran espacio de despliegue en la educación biocéntrica, forma educativa no convencional que propicia tempranamente espacios que facilitan la expresión corporal para lograr el desarrollo personal de niños y niñas, y la conexión con el medio que les rodea; tiene como desafío rescatar la parte instintiva desde acciones de lucha y fuga, amor indiferenciado, vínculo con la naturaleza, selectividad de alimentos y de conexión con todo aquello que permite la conservación y evolución de la existencia. En esta forma de educación, las personas que pertenecen a la comunidad son elementos fundamentales a la hora de diseñar el proyecto, tanto maestros como padres 
procuran llevar una vida coherente con lo que se está vivenciando en el aula. Según Toro (2006), a través de clases de biodanza y expresiones artísticas, niños y niñas descubren el valor del abrazo, de mirarse a los ojos y acariciar al compañero con ternura, cuidado y sin censura; también existe mucho trabajo parental recordando arquetípicamente que el continente afectivo y la responsabilidad con el semejante son principios indispensables en la formación inicial de un ser humano. A luz de estas reflexiones y caracterizaciones, es posible comprender con mayor claridad la propuesta de este texto.

\section{Valoración de párvulos y padres}

Según la Real Academia de la Lengua, párvulo proviene del latín parvus o parvulus que significa niño pequeño o de poca edad. También se puede asociar a conceptos de inocencia, ignorancia, candidez y humildad. Sin embargo, la sabiduría infantil tiene espectros de conocimientos originarios y esenciales que impactan en cada conversación sostenida con niñas y niños menores de seis años, el problema es que se subestima y se deja como anécdota aquel comentario o acción divertida de los más pequeños de nuestra sociedad. Según Carroll y Tober (2004), la mayor parte de los niños nacidos después del año dos mil, tienen una misión trascendente que comunicar; su limpieza espiritual y genuina son cualidades humanas que han venido a expandir en el mundo presente. Cuando actuamos en contradicción a la fluidez natural de la vida, ellos se manifiestan con gritos y desesperación kinética que altera entornos educativos infantiles (casa o jardín), pero somos los adultos los llamados a re-educarnos en el nuevo lenguaje de estos seres de luz, sólo debemos sintonizar con ellos y comprender su lenguaje verbal y corporal. Si bien los párvulos se caracterizan por ser inocentes, también algunos se distinguen por ser almas antiguas en cuerpos pequeños tratando de enseñarnos a vivir en armonía. A partir de lo anterior, es importante rescatar el conocimiento ontológico que tienen tanto niños como padres, y por esta razón difiero en algunas ideas de Tokman (2010: 3), cuando señala que:

Muchas veces los padres tienen falta de información disponible que permita diferenciar su calidad educativa, lo que puede conducir a no aprovechar plenamente los recursos que invierten en sus hijos. El Estado en este caso tiene un papel en asesorar a los padres acerca de los elementos importantes a considerar entre los oferentes de servicios y en exigir la provisión de información relevante, oportuna y comprensible para los usuarios. 
Este rol del estado se visualiza más desde un enfoque económico rentable que desde una transformación educativa real, donde la mirada se pone en aquello que los padres no saben hacer, y no en lo que sí saben. Quizás esta sea una de las causas de por qué los recursos inyectados en educación no tienen los resultados que se esperan. El no avance es fácil de detectar cuando se trabaja a partir de un pensamiento neoliberar y economisista, donde no se re-educa ni orienta a los padres, sólo se les sanciona, apareciendo de este modo un estado que dice tener las soluciones pertinentes para corregir lo que la familia está haciendo mal. ¿Existen evidencias y resultados positivos que demuestren las competencias educativas del estado de Chile para tales fines?

Lo que sí se puede considerar es el potencial educativo que tienen los padres y madres de los preescolares, nadie mejor que ellos saben, de manera consciente o inconsciente, lo que necesitan sus hijos, sólo basta validarles, comprenderles e invitarles a “ser el proyecto educativo" y no sólo a ser parte. Cuando no hay participación concreta y vivencial en el diseño de una propuesta pedagógica, es imposible que exista involucramiento. Es recurrente escuchar a educadoras quejarse de la falta de compromiso de la familia con sus hijos, relatos constantes manifiestan que los padres dejan a sus hijos en los jardines infantiles delegando poco a poco la responsabilidad educativa en las profesionales del párvulo, apareciendo de este modo sanciones de unas a otras instituciones: el gobierno educacional se queja de las educadoras y ellas de los modelos educacionales gubernamentales, y luego las educadoras sancionan a las familias y las familias a los dos actores anteriores. Este círculo vicioso no favorece en nada a los infantes, no es tan difícil ponerse de acuerdo, potenciar las virtudes y mejorar las debilidades, pero esto se logra sólo si se actúa como un todo comunitario que con-vive desde la inteligencia afectiva $^{3}$.

\footnotetext{
${ }^{3}$ En realidad, la inteligencia forma parte de todas nuestras funciones y de nuestra historia existencial; pensamos no sólo con el cerebro, sino con todo nuestro cuerpo. La inteligencia afectiva no es un tipo especial de inteligencia. Todas las formas diferenciadas de inteligencia, motora, espacial, mecánica, semántica, social, entre otras, tienen una fuente común llamada "afectividad". Para comprender esto, es necesario examinar las relaciones entre percepción, motricidad, memoria, aprendizaje, elaboración simbólica y lenguaje, con la estructura afectiva (Toro, 2012: 31).
} 
La invitación entonces es a terminar con las culpas de un lado hacia otro. La idea será jugar, danzar y reconocerse en el semejante, a través de la música y situaciones de encuentro. Biodanza aparece en este escenario como una gran oportunidad de validación del otro adulto que cuida, protege y ama al mismo niño (a).

\section{Biodanza con educadoras y padres en educación parvularia}

Los relatos siguientes, son experiencias docentes compartidas entre los años 2012 y 2015 en la Región de los Ríos, junto a educadoras de párvulos y apoderados de jardines infantiles desde el sistema biodanza y el principio biocéntrico.

\subsection{Experiencia I: biodanza, psicomotricidad y educadoras de párvulos}

En diciembre del año 2012, aparece la oportunidad de compartir biodanza con educadoras de párvulos en la comuna de Panguipulli - Región de los Ríos, junto a un especialista en psicomotricidad, quien posee vasta experiencia en el área. En general las educadoras siempre están pensando en actualizar sus conocimientos para mejorar sus prácticas docentes y facilitar de este modo el aprendizaje de niñas y niños, pero en pocas ocasiones solicitan cursos que apunten al autocuidado y el buen vivir. Nuestra propuesta fue una mixtura entre el cuidado esencial de la educadora y la entrega de recursos psicomotrices para trabajar en aula, siempre insistiendo en el diálogo corporal entre educadora y educando, dado que sin esta empatía cualquier metodología podría fracasar.

La propuesta consistió básicamente en un trabajo de tres días, divididos en dos jornadas cada vez, donde la música y el juego fueron elementos constantes de aprendizaje. Sólo en el primer encuentro se compartieron conceptos teóricos que darían el sustento epistémico de los próximas tareas a resolver. Recibirles con un abrazo y conversar sobre su agotamiento al finalizar el año, fueron elementos fundamentales al momento de despertar el interés de participar en este curso contratado por la municipalidad.

El abordaje de la psicomotricidad se realizó a partir del reconocimiento de los principios básicos que la fundamentan y su metodología en sala, reconociendo el juego sensoriomotor, el juego simbólico, el juego de representación y el rol facilitador del 
psicomotricista, como estrategias indispensables para el éxito de una sesión con preescolares.

Es precisamente en el rol facilitador del educador donde aparece el sistema biodanza como disciplina que refuerza y re-educa las habilidades docentes a partir de la valoración del sí mismo, de los otros y del entorno. ¿Cómo vamos a pensar en capacitarnos si no tenemos resueltas algunas preguntas básicas de existencia? Es aquí entonces cuando aparecen las siguientes interrogantes: ¿qué quiero hacer de mi vida?, ¿dónde y cómo quiero vivir y con quiénes quiero hacerlo?

En una ronda de mujeres cansadas pero colmadas de creatividad, no se esperan respuestas inmediatas ante preguntas tan profundas e invasivas, más bien se lanza la inquietud para remover el por qué y para qué de la existencia humana, lo demás se irá resolviendo desde el lenguaje corporal y no desde el hablado. Esta vez el curso de capacitación es un encuentro que prioriza la contención afectiva, comprendiendo que el propio cuidado será luego el cuidado del otro.

a) Ronda inicial: Comenzamos danzando en ronda tomadas de las manos junto a una música delicadamente alegre, donde la consigna es no cerrar los ojos y tampoco mirar el suelo; lo que se busca es entrar en sintonía visual con la compañera de al lado y también con las que están en frente; nadie somete a nadie y las manos entrelazadas son cariñosas al momento de balancear el cuerpo entero; las sonrisas aparecen espontáneamente y el grupo se saluda dando la bienvenida sin palabras que entorpezcan el mágico momento; la sala está temperada y los pies carecen de zapatos.

b) Marcha alegre con identidad: La siguiente tarea es caminar libremente por el espacio intentando la integración motora y el vaivén armónico de las caderas; la marcha es amplia y segura, lo hombros se abren y el corazón también; con música de "Queen, I'want to breake free", las participantes comienzan a reafirmar su identidad docente. Siempre el grupo vuelve al círculo por considerarlo un útero que contiene y radicaliza el ejercicio recién realizado. 
c) Juegos de vitalidad y creatividad: Luego de la marcha alegre con identidad, se sugieren ejercicios de vitalidad y creatividad donde se trabaja en parejas, tríos o grupos; la música siempre es festiva-euforizante para elevar el humor endógeno, las pulsaciones cardiacas y aumentar la producción de endorfinas como componentes del sistema adrenérgico. La creatividad por su parte, es abordada de diferentes formas y según la idea guía de la sesión; en ocasiones se pueden utilizar elementos concretos, como telas o cojines, pero lo primordial es el manejo y reconocimiento de las múltiples posibilidades del propio cuerpo y su vínculo estrecho con la música, donde más que bailarla se "es la música".

d) Descanso y semitransce: Cuando el grupo ya está excitado, es necesario descansar y dedicar un momento para que aparezcan los ejercicios de encuentros colectivos, nidos ecológicos o grupos de mecimientos. Es en esta instancia de la clase cuando se comienzan a subir los niveles de transce y entrega profunda, con el objetivo de disminuir la euforia y el desborde. Biodanza siempre desarrolla los polos opuestos y atrayentes: del caos al orden, del orden al caos; de la rapidez a la lentitud y de la lentitud a la rapidez; del yang al ying y del ying al yang; del ritmo a la melodía y de la melodía al ritmo. Ejercicios de fluidez, eutonía y desbloqueos de los centros energéticos son sólo algunos de los desafíos que propone el sistema biodanza en este momento de la sesión.

e) Encuentros: Llegando a la finalización de la sesión, es muy importante sellar las vivencias con encuentros de miradas, manos y/o abrazos, puesto que según su creador Rolando Toro Araneda, es en el abrazo donde una clase de biodanza radicaliza todas las vivencias anteriores; algunas lágrimas aparecen como significado del destape emocional y signo del desbloqueo emotivo. El cierre de la sesión de biodanza siempre es en una ronda alegre y amorosa, utilizando música que responde de manera armoniosa a la semántica musical que se ha venido trabajando. El grupo tomado de las manos gira hacia un lado de la ronda, celebrando y danzando el encuentro humano que generó lazos, empatía y reafirmación del yo porque existe el tú. 
De esta manera, se fue repitiendo una sesión por día, para luego plasmar la vivencia a través de alguna expresión artística visual que permitiera transferir la experiencia corporal y emotiva de las educadoras. Específicamente se trabajó con greda y confección de colages con materiales variados y alternativos: semillas, lanas, cintas, plumas, fideos, lentejuelas, entre otros. Ambas técnicas (greda y colage), tenían la consigna de ser trabajadas de manera colectiva salvaguardando las emociones individuales, vale decir, construir obras en gran formato donde cada parte finalmente formaría parte del todo.

Esta metodología realizada con adultos, generó complicidad entre el equipo docente, además de sonrisas, concentración y placer; lograron reconocer aprendizajes desde el conocimiento de sí mismo y las características individuales de cada participante. Quizás uno de los resultados más valiosos fue la confección comunitaria de una sola obra donde se valora el aporte de la diferencia en un bien común.

Es relevante destacar que el facilitador (a) de biodanza nunca debe traducir verbalmente lo que piensa o cree que significa un trabajo, si bien se pueden deducir ciertos aspectos de personalidad, el sistema es muy respetuoso de la psicología clínica como profesión de especialistas. La idea es que cada participante o el mismo grupo determine qué es lo que se quiso expresar, pero en ningún caso lo hará el profesor, el caer en esta tentación podría desajustar y desarmonizar la vivencia de danza anterior. Otro cuidado importante, es no verbalizar la vivencia durante la misma clase, el pensamiento y la palabra son condiciones occidentalizadas que atrapan el conocimiento esencial de cada ser humano; en biodanza se procura utilizar los sentidos menos requeridos en lo cotidiano; escucha, olores, caricias y desplazamientos son elementos perceptivos de vital importancia a la hora de lograr homeostásis corpórea.

\subsection{Experiencia II: biodanza y comunidad rural}

Durante la experiencia recién relatada, hubo una de las educadoras que al año siguiente, 2013, retomó contacto y propuso llevar biodanza a toda su comunidad educativa. En la ocasión, expuso que biodanza removió en ella muchas zonas emotivas un tanto bloqueadas, y quería compartir estas vivencias con diversas personas del jardín que dirigía ubicado en un sector rural de la misma provincia; la directora y educadora de párvulos comprendió que 
para mejorar los aprendizajes de niños y niñas era necesario trabajar en red, por lo tanto la invitación esta vez era realizar un ciclo de módulos de biodanza para técnicos/asistentes en educación parvularia, apoderados, manipuladora de alimentos y algunos vecinos del jardín infantil Peumayén, perteneciente a la localidad de Choshuenco, Panguipulli, Región de los Ríos.

Sin duda, el presente desafío fue una gran oportunidad de profundizar conceptos, metodologías y vivencias. La iniciativa se financió vía proyecto a través de una empresa privada de la zona. Por su parte, la metodología diseñada contempló tres meses de trabajo, con una periodicidad de sesiones cada quince días, donde se dedicaban tres horas de trabajo por vez: noventa minutos para vivencia y noventa minutos de metacognición y asimilación de conceptos. La idea central fue desarrollar una didáctica que se abordara desde la práctica a la teoría, donde danzas y juegos rítmicos serían herramientas claves para despertar la creatividad y por consecuencia reafirmar la identidad docente. Los módulos trabajados se describen a continuación:

Módulo 1 = Biodanza y fortalecimiento de la identidad

Biodanza es la danza de la vida inspirada en los orígenes más primitivos del ser humano, donde su expresión no es figurativa sino una danza orgánica en grupo. Es una invitación a conectarse con todo lo vivo desde un espacio sagrado, donde se celebra la existencia mediante ciertas danzas que activan potenciales afectivos y de comunicación. En este módulo se trabajó el fortalecimiento de la identidad, entendida como la conexión vital y esencial de la persona expresada en todo su potencial filo y ontogenético. Cuando se ejercita y recupera la identidad, se logra la sintonía de nuestras partes internas como también el entramado cuerpo-alma tanta veces disociados. Según las investigaciones de Rolando Toro (creador de la biodanza), basadas en los pensamiento de Jung (2009) y Bachelard (2000) en torno al simbolismo arquetípico de los cuatro elementos de la naturaleza, la identidad de un individuo tiene componentes de tierra, agua, fuego y aire, y las mayores dificultades humanas surgen cuando alguno de éstos no puede manifestarse con esplendor (López, 2011). En este primer encuentro con la comunidad educativa, se 
realizaron principalmente ejercicios de reforzamiento de la identidad personal, social y cósmica, sellando los aprendizajes a través de la confección de un gran mandala colectivo.

Módulo 2 = Biodanza y educación biocéntrica

Durante los primeros años de vida se desarrollan de manera más rápida y eficiente las facultades sensoriales y perceptivas. La educación biocéntrica propicia tempranamente espacios que facilitan la expresión corporal, para lograr el desarrollo personal del infante y la conexión con el medio que lo rodea. Según los primeros pensamientos de Rolando Toro (como profesor y psicólogo), la educación debe rescatar la parte instintiva de los niños, vale decir, los instintos de lucha y fuga, de amor, de vínculo con la naturaleza, de selectividad de los alimentos y, en general, de conexión con todo aquello que permite la conservación y evolución de la vida. Este módulo estuvo dedicado a orientar la educación parvularia hacia la sobrevivencia y restablecimiento de las funciones originarias; el enfoque fue comprender que todos los procedimientos pedagógicos deben ser practicados con la frecuente participación de la familia y la comunidad circundante, dando al espacio educativo la forma de una "escuela universo". Los ejercicios dancísticos esta vez se desarrollaron en torno a tareas de intensidad, afectividad, semitransce y comunidad.

Módulo 3 = Biodanza, creatividad e infancia

La creatividad es la "capacidad de renovación aplicada a la propia vida, o sea poner creatividad en cada acto" (Toro, 2008: 117). En este sentido biodanza permite la expresión de la identidad, desarrolla la creatividad y despierta en las personas su condición trascendente al vincularlas con la armonía del universo. Cuando se realizan tareas de este tipo "se integran la danza, la música, la psicología, la biología y la filosofía" (Toro, 2012: 82). La creatividad tiene que ver con la expresión y la libertad de ser. No se refiere sólo a lo artístico sino a la auto-creación existencial, está relacionada con la curiosidad innata y el instinto exploratorio. "En el ser humano, la creatividad se manifiesta como impulso de renovación frente a la realidad" (Cit. en Toro y Terrén, 2008: 55). Los estímulos sensoriales y creativos en los niños vienen desde el vientre materno, y es desde ese momento que se comienzan a tejer lazos afectivos profundos que permiten registrar experiencias en la formación de cada célula del feto. En este contexto, no se puede desconocer que cuando 
llega un nuevo integrante a la familia ésta se re-estructura y se re-crea, abriéndose múltiples posibilidades de transformación humana que invitan al juego, al canto y a las sonrisas, todas ellas características propias de la creatividad. Para Fontoura (2011), la sociedad actual está conformada por adultos ansiosos que se mudan y transforman demasiado rápido en relación a los tiempos de asimilación de aprendizaje de un niño, produciendo de este modo una incapacidad de escucha corporal que luego se podría traducir en el bloqueo de sensibilidades que conllevan a la capacidad de crear. Por esta razón, en este módulo se trabajaron fundamentalmente ejercicios de expresividad, humor endógeno, sensibilidad y lectura corporal.

\section{Módulo 4 = Música, biodanza y elementos creativos}

Existen dos líneas de experiencia musical que son una infraestructura biológica: la música orgánica y la música inorgánica (Toro, 2012). Se define como música orgánica a casi todas las formas de música tradicional que contienen atributos biológicos: fluidez, armonía, ritmo, tonos, unidad de sentido. Dentro de este grupo estarían todas aquellas músicas estructuradas a partir de un núcleo musical o de un propósito fuertemente expresivo, como ocurre por ejemplo con los conciertos de Vivaldi. El advenimiento de la música contemporánea se caracteriza por haberse desligado progresivamente de los atributos de lo orgánico, en este caso la música electrónica, la concreta, el serialismo, la sintética, y la música aleatoria o del azar, tienen dos elementos en común: el haberse tornado cada vez más reflexiva y abstracta, y haber abandonado la coherencia en el tiempo y la fluidez de lo orgánico. La música en biodanza debe tener una forma de energía capaz de estimular el despertar de potenciales biológicos y emocionales, y como primera exigencia debe tener un sentido de unidad y desarrollo coherente. A partir de ello, se puede comprender que la inteligencia musical es la cualidad específica de comunicar vida. Durante este encuentro los ejercicios de biodanza estuvieron orientados desde el reconocimiento corpóreo de los contraste musicales ofrecidos, donde los participantes debían resolver tareas de identificación entre ritmo y melodía, rápido y lento, ying y yang, tierra y aire, entre otros. Complementario a ello, se utilizaron telas y objetos que colaboraron con los desafíos 
propuestos, siempre desde la valoración de la estética de la expresión, la danza, la belleza de la música y la importancia de armonía en la vida cotidiana.

Módulo 5 = Signos y símbolos de la sesión de biodanza

La base de la metodología en biodanza es "la vivencia". Uno de los principales investigadores de la vivencia fue Wilhelm Dilthey en el año 1949, y la definió como algo revelado en el complejo psíquico de un individuo, dado en la experiencia interna de la realidad de éste. Para Toro (2008: 33), vivencia se define como "experiencia vivida con gran intensidad por un individuo en el presente, que compromete la cenestesia, las funciones vicerales y emocionales". La finalidad de inducir vivencias es la integración y el desarrollo humano mediante la estimulación de la función arcaica de conexión con la vida. Según Skinner (Cit. en Toro, 2008: 33), "un aprendizaje se estabiliza mejor cuando se incentiva lo positivo". A partir de lo anterior, se puede inferir que el fenómeno del aprendizaje compromete todo el organismo y no sólo las funciones corticales, ya que la percepción de los significados que condicionan la existencia, puede influir sobre la esfera emocional y sobre la esfera viceral. Desde esta mirada, en biodanza el aprendizaje se plantea en tres niveles: cognitivo, vivencial y viceral. Estos tres niveles están neurológicamente relacionados y pueden condicionarse recíprocamente, aunque posean además una fuerte autonomía. En biodanza se va de la emoción a los significados, siendo en ese instante cuando la vivencia tiene un efecto inmediato de integración, por lo tanto no es necesario que sea posteriormente analizada a nivel de la conciencia, pero si se puede hacer una descripción personal de la vivencia que no involucre análisis e interpretación psicológica. En esta sesión se realizaron esencialmente ejercicios de gestualidad sutil, miradas y abrazos profundos, posiciones generatrices y exaltación de la presencia.

Módulo 6 = Evaluación de la biodanza desde principios no convencionales

En este módulo se trabajó la forma de evaluar los aprendizajes en biodanza, abordando perspectivas didácticas no convencionales y ligadas más bien al lenguaje artístico y al autorelato. Se propuso la bitácora como medio de comunicación que registra los hechos anecdóticos relevantes de un participante. También se agregaron talleres de desarrollo personal (escritos) donde los participantes pueden responder preguntas con sentido de 
existencia y luego compartirlas con el grupo, sólo si lo estima conveniente. Los relatos de vivencia son la forma de evaluación más tradicional en biodanza; en ellos se busca constituir una fenomenología hablada en la cual el alumno describe algunos aspectos íntimos, personales y que adquieren la categoría de revelación de los procesos más importantes de su experiencia interior durante la sesión; el relato de vivencia al emplear el lenguaje, genera un proceso de duración del significado en el tiempo, porque a través de la palabra se manifiestan componentes simbólicos y se aumenta la conciencia de la experiencia vivida; es un recurso verbal, por lo tanto no puede designarse a biodanza como una disciplina meramente no verbal; el relato de vivencia no es un diálogo terapéutico y no prevé ninguna forma de interpretación; se realiza siempre al comienzo de la sesión y jamás al final, dado que como se ha mencionado antes, la activación cortical provocada por el lenguaje hablado anula los efectos psicofisiológicos producidos por las danzas. Finalmente, se presenta la posibilidad de radicalizar los aprendizajes por medio de pinturas y grafismos. En ellas pueden hacerse visible lo jamás visto; en el arte es indispensable la revelación de significados, formas y colores que abran puertas a lo desconocido, entregándose a las revelaciones de lo inesperado; en algunos cuadros de Van Gogh por ejemplo, como "Los Girasoles", se siente aquella agitación interna que genera el mundo, activando centros del cerebro humano que inducen a la expansión de conciencia; Rolando Toro afirma que las obras de dicho autor, podrían producir estados afectivos excepcionales de amor infinito.

\section{A modo de conclusión y apertura}

Tanto las vivencias descritas como los datos teóricos y epistémicos que entretejen esta propuesta, son quizás uno de los primeros pasos para aventurarse en el tema de cuidado y buen vivir docente. No son sólo las educadoras de párvulos y su comunidad las que necesitan re-aprender a vivir, somos los adultos todos los que olvidamos la esencia de ser niños, y es en esta especie de muerte cerebral y espiritual, donde hay que aplicar cirugía amorosa para lograr la recuperación. Los potenciales de felicidad, vitalidad y pasión están esperando su oportunidad para aparecer nuevamente, y digo nuevamente porque cuando fuimos niños estas cualidades eran innatas, por lo tanto la única magia de estas disciplinas es despertar aquello que está adormecido. En este removimiento de cualidades, Wagner 
(2012) plantea que la vivencia biocéntrica emerge de la vida instintiva y recorre caminos variados desde el interior hacia el exterior, a través de canales biológicos de expresión de la identidad personal, por tanto conviene distinguir las diferencias entre experiencia y vivencia.

Según García (2014), la experiencia se opone a la vivencia puesto que la primera es siempre un fenómeno cognitivo, predominantemente abstracto y que representa lo vivido en forma de pasado. Mientras que la vivencia al tener siempre cualidad somática, tiende a demoler las estructuras prejuiciales que nos impiden vivir plenamente, cumpliendo una función desculpabilizadora a través de la afectividad, el goce cenestésico y el continente gregario que liberan la identidad por medio de la armonía y la fluidez con la vida. Complementario a ello, es indispensable reconocer que dentro de la vivencia profunda, la consigna es des-aprender más que aprender y diluir más que armar y enrigidecer, por eso el facilitador nunca posee la verdad.

El sistema biodanza y el principio biocéntrico son sólo una de las tantas metodologías alternativas que deberían incorporar los ministerios de educación en el mundo, quizás también los saberes de Edgar Morín, los planteamientos de Paulo Freire, la sabiduría de María Montessori y la sensibilidad de Gabriela Mistral.

Si sanamos los mayores, aprendemos a valorarnos y decidimos aprender de nuestros niños, es muy probable que demos un salto cuántico hacia una mejor calidad de vida y por lo tanto a una mejor calidad educativa. ¿Será posible que los gobiernos y los expertos en educación comprendan que no basta con algunas sesiones de "coaching educativo" para lograr verdadero buen vivir en las aulas? La apuesta es que el auto-ecocuidado sea una formación permanente y obligatoria, la identidad docente y humana es algo que se gana y se pierde todos los días, y una forma precisa de abordarla es desde la corporeidad, y no sólo desde el discurso hablado.

\section{Referencias bibliográficas}

Albó, X. (2009). Suma qamaña, el buen vivir. Obets, 4, 4, 25-40. 
Álamo, M. (2011). La idea de cuidado en Leonardo Boff. Tales, 4, 4, 243-253. Consulta realizada 28 julio 2015. http://www.revistatales.wordpress.com.

Alonso, S. (2014). ¿Qué es la biodanza? ¿Cómo nace? El principio biocéntrico, como motor impulsor de la biodanza. Espacio Esencial, 9, 9, 1-4. Consulta realizada 5 mayo 2015. http://www.holista.es/spip/article207.html.

Bachelard, G. (2000). La poética del espacio. Buenos Aires/México D.F: Fondo de Cultura Económica de Argentina.

Boff, L. (2006). Ecología: grito de la Tierra, grito de los pobres. Madrid: Editorial Trotta.

Carroll, L. y Tober, J. (2004). Los niños índigo. Barcelona: Ediciones Obelisco.

Fontoura, A. (2011). Prácticas en educación infantil. Pensamento Biocéntrico, 16, 16, 7-24. $\begin{array}{lllll}\text { Consulta } & \text { realizada } & 25 & \text { julio }\end{array}$ http://www.pensamentobiocentrico.com.br/content/index.php.

García, C. (2014). Vivencia, corporalidad e inmanencia. Pensamento Biocêntrico, 21, 21, 37-53. Consulta realizada 25 julio 2015. http://www.pensamentobiocentrico.com.br/content/index.php.

Jung, C. (2009). Arquetipos e inconsciente colectivo. Barcelona: Editorial Paidós Ibérica.

López, N. (2011). La identidad y los cuatro elementos. Biodanza Hoy, 1, 1, 26-28. Consulta realizada 15 mayo 2015. http://www.biodanzahoy.cl/revista/bio1.pdf.

Tokman, A. (2010). Radiografía de la Educación Parvularia Chilena: Desafíos y Propuestas. Documentos de Trabajo, 5, 5, 1-55. Consultada 08 junio 2015. http://www.expansivaudp.cl/publicaciones/wpapers/.

Toro, R. (2006). Biodanza y educación. Pensamento Biocêntrico, 6, 6, 70-76. Consultada 30 julio 2015. http://www.pensamentobiocentrico.com.br/content/index.php.

Toro, R. (2008). Biodanza. Santiago de Chile: Editorial Gedisa.

Toro, R. (2012). Inteligencia afectiva: la unidad de la mente con el universo. Editado por Cecilia Toro/Póstumo. Santiago de Chile: Editorial Cuarto Propio. 
Toro, V. y Terrén, R. (2008). Biodanza poética del encuentro. Buenos Aires/México D.F: Grupo Editorial Lumen.

Wagner, C. (2012). Psicología clínico-comunitaria. Fortaleza: Banco do Nordeste. 